\title{
Selective location of palisaded myofibroblastoma with amianthoid fibres
}

\author{
G Bigotti, A Coli, M Mottolese, F Di Filippo
}

\begin{abstract}
The occurrence of a palisaded myofibroblastoma with amianthoid fibres in the left inguinal lymph node of a 51 year old man prompted an investigation of the factors underlying its exclusive location. The antigen profile was characterised which confirmed the homogeneous expression of vimentin and smooth muscle actin as well as the lack of desmin. Use of monoclonal antibodies to check for a differential distribution of myofibroblasts and the putative cell of origin of palisaded myofibroblastoma showed that inguinal lymph nodes have abundant vimentin and actin positive cells and desmin negative cells. This suggests that the selective occurrence of myofibroblastoma is related to the nodal microenvironment, providing a source of available and potentially proliferating myofibroblasts. Mast cells abounded in this lesion, particularly around amianthoid fibres, as well as in pelvic and inguinal lymph nodes.

In view of the known role of mast cells in interstitial matrix degradation it is postulated that the core of amianthoid fibres represents degraded interstitial matrix, analogous to the sclerotic areas commonly found in the above mentioned lymph node groups, while the peripheral spokes, so peculiar to this entity, are the result of vimentin and smooth muscle actin, directly shed by proliferating myofibroblasts.
\end{abstract}

Primary tumours of the lymph nodes, excluding those of lymphoid origin, are rare. Apart from Kaposi's sarcoma which occurs in those with AIDS, ${ }^{1}$ melanocytic nevi, and pseudosarcomatous malignant melanomas from displaced nevic cells, ${ }^{2}$ other primary lymph node tumours are uncommon. Secondary spindle cell tumours are represented by malignant melanomas, pseudosarcomatous carcinomas, ${ }^{3}$ and metastatic sarcomas. We report the occurrence of a primary spindle cell tumour in an inguinal lymph node with the classic features of the so-called "palisaded myofibroblastoma with amianthoid fibres." We attempt to explain its selective occurrence in inguinal lymph nodes by investigating the differential myofibroblastic content of lymph nodes of various sites. We also try to explain the histogenesis of the amianthoid fibres typical of this entity.

\section{Methods}

Tumour specimens were fixed in $10 \%$ formalin and embedded in paraffin wax. Hematoxylin and eosin stained sections were examined by light microscopy to establish the diagnosis. Tissue sections were also stained with Masson's trichrome, Van Gieson stain, Gomori's methenamine silver, reticulin stain, Congo red, Giemsa and methylene blue.

Ten to 15 tumour free lymph nodes from each of lateral cervical, axillary, mediastinal, abdominal, lumboaortic, pelvic and inguinal regions were obtained from patients undergoing surgery, primarily for cancer. Tissue specimens were routinely processed and stained for histopathological diagnosis. Giemsa and methylene blue stains were used to evaluate the mast cell content. For immunohistochemistry $4 \mu \mathrm{m}$ thick tissue sections from both the tumour and the various lymph nodes, chosen as previously described, were dewaxed in xylene and hydrated in graded ethanol; endogenous peroxidase activity was blocked with methanolic hydrogen peroxide and slides were subsequently washed in phosphate buffered saline (PBS). The sections were then processed for immunoperoxidase according to the method of Hsu et al. ${ }^{4}$

The reagents were purchased from Vector Laboratories (Vectastain, Burlingame, California, USA). The staining reaction was developed with 3,3-diaminobenzidine tetrahydrochloride. Sequential sections from each of the lymph node blocks-that is, sections of tissue with virtually identical architecturewere examined to compare their immunoreactivity after staining with monoclonal antibodies. The following antibodies were used at dilutions suggested by the manufacturer: S100 protein (Dako); vimentin (Dako); smooth muscle actin (Ortho); desmin (Dako); and factor VIII (Dako). S100 and factor VIII antobodies were applied only to sections of tumour.

Negative controls included tissue section incubation with normal horse serum or PBS buffer instead of the primary antibody. Positive controls consisted of normal intestinal wall, and malignant melanoma; they displayed strong and specific immunorectivity.

After being stained with Giemsa and methylene blue immunohistochemically stained cells and metachromatic mast cells were counted in each of 20 randomly selected fields using a medium power objective $(\times 250)$ and a field average was calculated for each of the different lymph node groups. 


\section{Case report}

A 51 year old man presented with a swelling of the left inguinal region of two years duration and recent increase in size. A lymph node, measuring $2 \times 3 \mathrm{~cm}$, was recovered at surgery. Fine needle aspiration biopsy had led to a cytological diagnosis consistent with schwannoma. A frozen section was cut and interpreted as haemorrhagic infarct of the lymph node. On cut section the lymph node seemed to have been replaced by grey-white tissue with a prominent rim of blood at the periphery and flecks of bleeding in the tumour tissue itself.

The patient remained well with no recurrence one year after excision.

\section{Results}

\section{MYOFIBROBLASTOMA}

Histological examination of formalin fixed, paraffin wax embedded tumour showed a

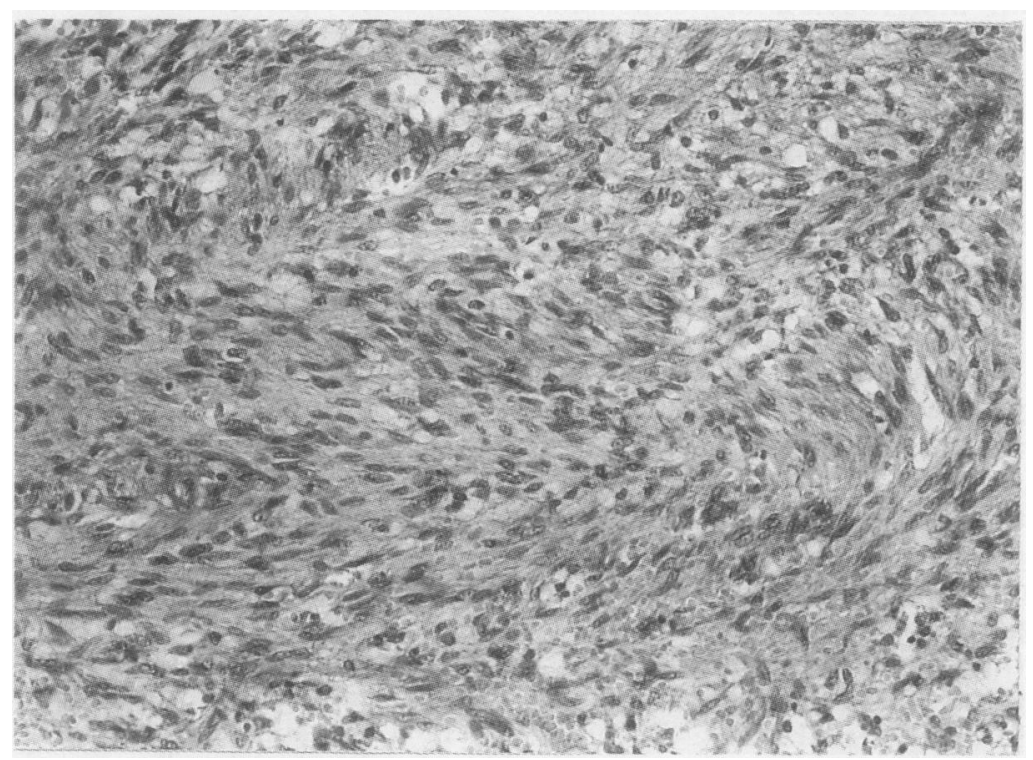

Figure 1 Palisaded myofibroblastoma showing fascicles of elongated cells with tapered nuclei and pale cytoplasm.

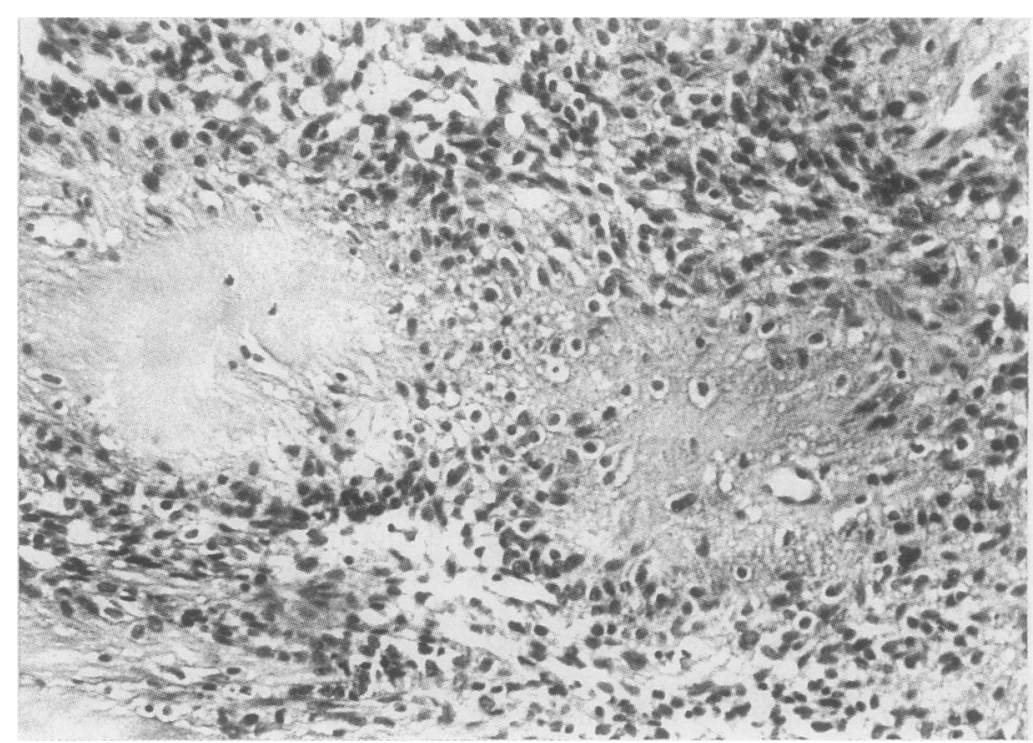

Figure 2 Section of an early phase of amianthoid fibre formation, in which a vessel is beginning to be surrounded by collagen. Overlaying is an almost fully formed amianthoid structure. Both seem to be surrounded by proliferating myofibroblasts. proliferation of spindle cells with elongated, tapered nuclei and weakly staining eosinophilic cytoplasm lacking distinct fibrils (fig 1). The tumour cells were arranged in bundles sometimes intersecting at acute angles and in some areas showing distinct palisading of the nuclei. Throughout the tumour there were multiple collections of an intensely eosinophilic collagen matrix which were generally oval in shape and had peripheral spokes strictly contiguous with proliferating cells. In a few areas these collections of eosinophilic matrix seemed to be centered around blood vessels (fig 2). The tumour was circumscribed by a thick collagenous capsule and beyond the capsule remnants of lymph node with marginal sinuses were found. The tumour was also haemorrhagic, and in many areas red blood cells were seen within the interstitium among proliferating cells. Less than two mitoses per 50 high power fields were found.

Trichrome and Van Gieson stains did not show distinct longitudinal fibrils in tumour cells and the amianthoid fibres had the features of strongly stained collagen at their coresblue with Trichrome and red with Van Gieson (fig 3). Gomori's stain gave the amianthoid fibres a strong black colour; they were Congo red stain positive and appeared birefringent under polarised light. Giemsa and methylene blue stains showed numerous mast cells with metachromatic granules, which clustered around the amianthoid fibres (fig 4) and which were diffusely scattered far away from the latter in areas of active cellular proliferation.

Immunohistochemistry showed tumour cell staining for vimentin and smooth muscle actin (fig 5), while immunostaining for desmin, factor VIII, and $\mathbf{S 1 0 0}$ was consistently negative. The positivity in all cases was cytoplasmic. The amianthoid fibres were negative for all the immunocytochemical markers except in the spokes contiguous with cell proliferation where positivity for vimentin and actin could be observed (fig 5). S100 and antifactor VIII antibodies stained, respectively, only rare nerve bundles and vascular endothelia.

\section{LYMPH NODES}

Giemsa and methylene blue stains showed numerous mast cells, especially around areas of sclerosis in pelvic, inguinal, and lumboaortic lymph nodes. By contrast, mast cells were scarce and isolated in other lymph node groups. In all the locations examined mast cells had a preferential distribution in lymph sinuses, toward the medulla, and around areas of sclerosis where this was present.

Immunostaining of lateral cervical, axillary, mediastinal, abdominal, lumboaortic and pelvic lymph nodes highlighted a striking paucity of smooth muscle actin, vimentin positive, desmin negative elongated cells (fig 6); these were identified mainly in the capsule and fibrous septa. Smooth muscle, stained by monoclonal antibodies to vimentin, smooth muscle actin, and desmin, was present in vessel walls and bundles of elongated cells in the capsule, and in lesser numbers in fibrous trabeculae. Occasional, rare, and isolated des- 


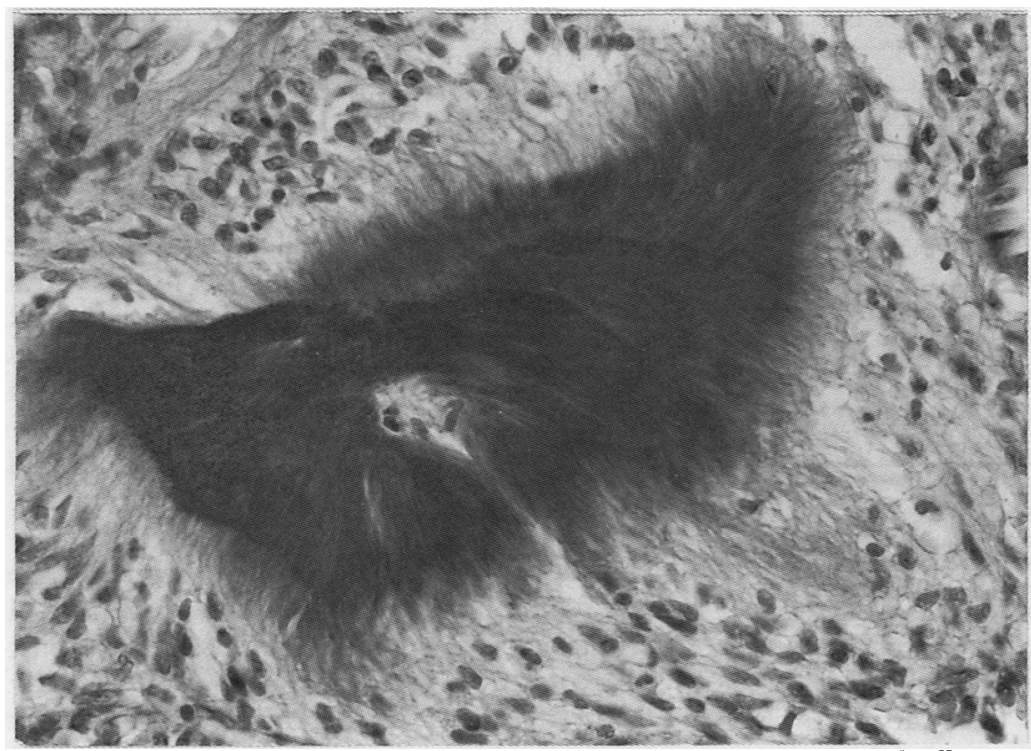

Figure 3 The so-called "amianthoid fibres" seem to be composed of a central collagen core and peripheral spokes, as shown here. Note that this structure is strongly stained by Van Gieson and is centered by a blood vessel.

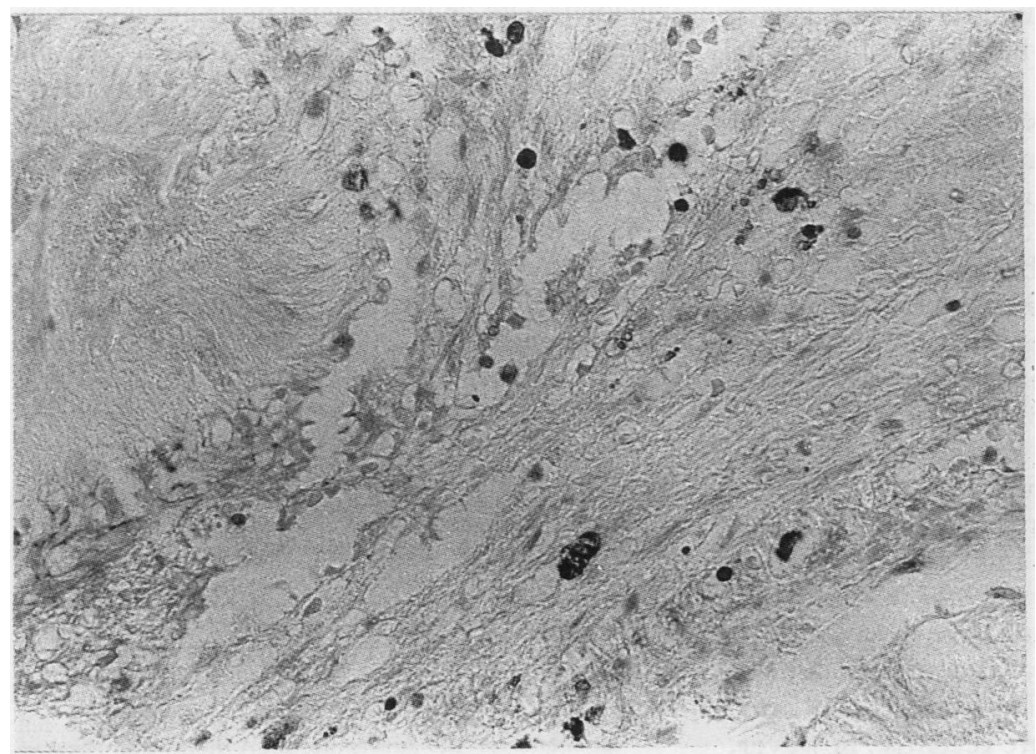

Figure 4 Numerous methylene blue stained mast cells are seen around amianthoid fibres and among proliferating tumour cells.

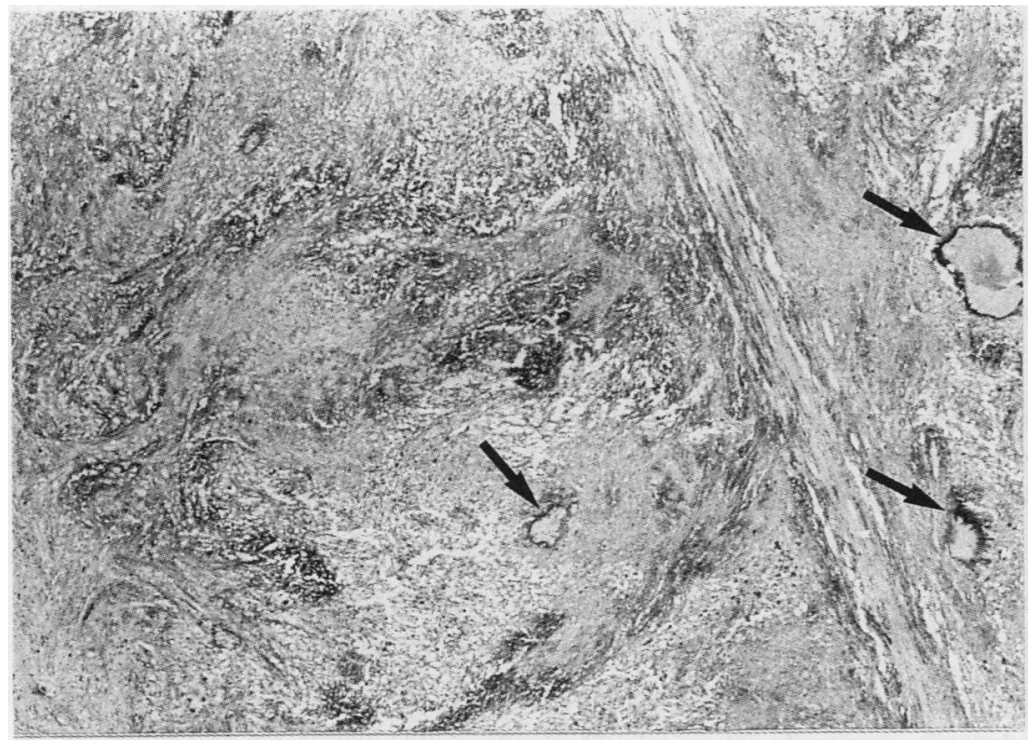

Figure 5 Section of palisaded myofibroblastoma showing dark staining smooth muscle actin positive tumour cells and spokes of amianthoid fibres (arrows).

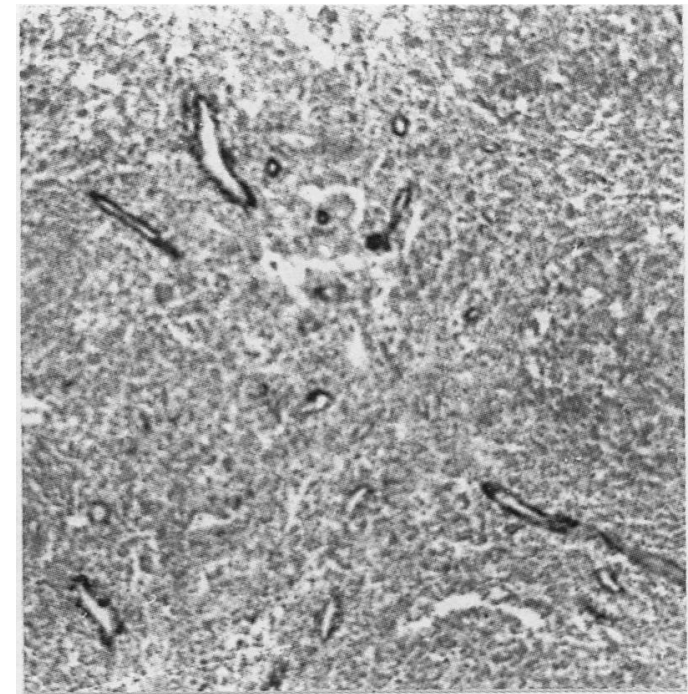

Figure 6 Smooth muscle actin antibody stains only the vessel walls in this abdominal lymph node. Note the virtual absence of immunostained interstitial cells.

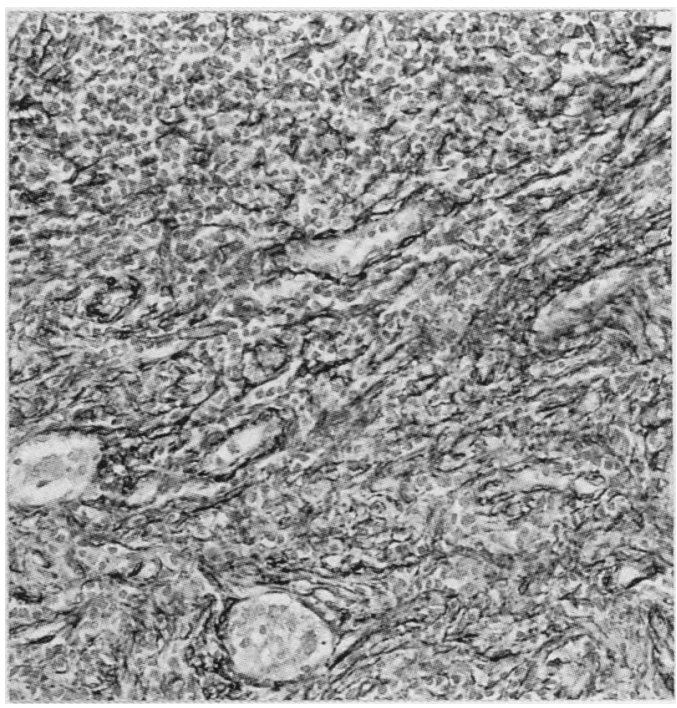

Figure 7 Section of inguinal lymph node showing numerous smooth muscle actin positive interstitial cells interdigitating with lymphocytes.

min positive cells, sometimes of reticular shape, were seen between lymphocytes.

In contrast, inguinal lymph nodes had large numbers of elongated, vimentin and actin positive, desmin negative cells, which were widespread in the capsule, fibrous septa, and interdigitating with the lymphoid tissue (fig 7). Their distribution was predominantly subcapsular, paracortical, sinusoidal and toward the medulla, and virtually never in follicles and in particular not in germinal centres. These cells seemed particularly abundant and clustered around areas of sclerosis. Their immunocytochemical staining was cytoplasmic.

Inguinal lymph nodes, stained with the desmin monoclonal antibody, had an immunoreactivity pattern similar to that of other lymph node regions, with only rare and isolated stained cells, identified mainly in the subcapsular and paracortical areas.

The table summarises the mast cell count and the actin and desmin immunoreactivity in the different lymph node groups.

\section{Discussion}

We have reported a rare entity ${ }^{56}$ which is thought to arise selectively in inguinal lymph 
Table Immunoreactive cells and mast cell detection in various lymph node sites

\begin{tabular}{|c|c|c|c|c|}
\hline Case No & $\begin{array}{l}\text { No of } \\
\text { lymph nodes }\end{array}$ & Actin & Desmin & Mast cell count \\
\hline $\begin{array}{l}1 \text { inguinal } \\
2 \text { inguinal } \\
3 \text { iliac } \\
4 \text { iliac } \\
5 \text { iliac } \\
6 \text { obturator } \\
7 \text { aortocaval } \\
8 \text { peripancreatic } \\
9 \text { perigatric } \\
10 \text { mediastinal } \\
11 \text { axillary } \\
12 \text { axillary } \\
13 \text { lateral-cervical }\end{array}$ & $\begin{array}{l}15 \\
10 \\
10 \\
13 \\
12 \\
12 \\
14 \\
10 \\
13 \\
10 \\
12 \\
13 \\
11\end{array}$ & $\begin{array}{l}++ \\
++ \\
+ \\
- \text { to }+1- \\
+1- \\
+ \\
+ \\
- \text { to }+1- \\
- \text { to }+1- \\
+1- \\
-\end{array}$ & $\begin{array}{l}- \text { to }+1- \\
- \text { to }+1- \\
- \\
- \\
+1- \\
+ \\
+1- \\
- \text { to }+1- \\
- \\
- \text { to }+1- \\
- \text { to }+1- \\
-\end{array}$ & $\begin{array}{l}++ \\
++ \\
+ \\
++ \\
- \text { to }+1- \\
++ \\
++ \\
- \\
- \\
- \text { to }+1- \\
- \text { to }+1- \\
-\end{array}$ \\
\hline
\end{tabular}

Key: immunostained cells present only in the capsule and thick septa. One or no mast cells per medium power field (MPF); $+/-=$ immunostained cells in the lymphoid tissue; one or no stained cells per MPF, two to four mast cells per MPF; $+=$ few to moderate immunostained cells in the lymphoid tissue, two to 10 stained cells per MPF, five to 10 mast cells per MPF; $++=$ numerous immunostained cells in the lymphoid tissue, 11 or more stained cells per MPF, 11 or more mast cells per MPF; - to $+l-=$ average obtained from two contiguous values.

Note. Capsular and trabecular immunostaining was observed in all the lymph nodes examined.

nodes. Its recognition is of great importance because of its possible confusion with a primary malignant or metastatic spindle cell tumour.

Palisaded myofibroblastoma, a term first used by Weiss et al, ${ }^{5}$ can closely simulate Kaposi's sarcoma, which in patients with AIDS can occur as a primary in lymph nodes; this is particularly evident when the interstitial haemorrhage resembles the extravasated red blood cells seen in Kaposi's sarcoma. The lack of true vascular slits and nuclear atypia, as well as to the extreme rarity of mitotic figures, will usually indicate the correct diagnosis. Furthermore, Kaposi's sarcoma has a sinusal distribution, and when lymphoid tissue is present it is always located deep within the tumour and not at the periphery, as seen in myofibroblastoma. ${ }^{7}$

The histogenesis of this entity is not completely understood but it is suggested that the cell of origin is the myofibroblast, ${ }^{5}$ first described by Gabbiani et al in granulation tissue as well as in quasineoplastic and neoplastic conditions such as in various types of fibromatosis. ${ }^{89}$ It displays a generally distinct antigenic profile that is characterised by the expression of vimentin, smooth muscle actin, procollagen type I, III, and V; ${ }^{10}{ }^{11}$ more recently, however, the existence of different phenotypic subsets of myofibroblasts has been pointed out. ${ }^{12}$ Palisaded myofibroblastoma is characterised by the continuous expression of actin and vimentin and by the lack of desmin, ${ }^{5}$ as seen in our case. Its selective occurrence has prompted us to investigate the possibility of a differential myofibroblastic distribution according to the lymph node site.

Our results indicate that actin positive, desmin negative myofibroblasts are strikingly prominent in inguinal lymph nodes where they are diffusely present as opposed to other lymph node chains. In this context palisaded myofibroblastoma could represent a quasineoplastic or neoplastic proliferation in a group of lymph nodes subject to a striking degree of drainage function and massive workload.

The numerous vimentin positive, smooth muscle actin positive, desmin negative cells we have described in the inguinal lymph nodes could be smooth muscle cells and not myofibroblasts, but in this instance one would have expected to find a much higher percentage of reactivity with the desmin monoclonal antibody because smooth muscle cells, though characterised by a variable percentage of desmin expression, should nevertheless show a reactivity of at least $50 \% .^{11}$

We feel that mast cells may have a crucial role, both in the formation of amianthoid fibres and in the active proliferation of myofibroblasts in myofibroblastoma. In fact, mast cells have been shown to be involved in interstitial matrix degradation and to be potent stimulators of fibroblasts and of tumour cell proliferation, an action mediated by histamine and heparin release. ${ }^{1314}$

In our study we have shown a differential distribution of mast cells according to the lymph node region and their preferential location in sinuses and around areas of sclerosis, the latter commonly found in otherwise normal inguinal and pelvic nodes; in this context mast cells could be responsible for sclerosis by releasing protease in the intercellular matrix and around blood vessels.

The same mechanism could operate in the production of the collagen core of the amianthoid fibres of palisaded myofibroblastoma. Suster et $a l^{6}$ showed that it is composed of degraded collagen. The characteristic peripheral spokes, composed of vimentin and smooth muscle actin, would then probably represent intermediate filaments directly extruded from the massively proliferating myofibroblasts at the interface with such a core.

The recognition of palisaded myofibroblastoma remains very important, especially in view of the uniformly favourable prognosis (lack of recurrence, local invasion, and systemic spread) as seen in our case as well as in the others previously reported.

We are grateful to $T$ Prosperi and A Ruggeri for excellent technical assistance and to G Rosi, R Mallucci, and B Ghirott for photographic assistance.

1 Finkheiner WE, Egberst BM, Groundwater JR, Sagabiel RW. Kaposi's sarcoma in young homosexual men. A histologic study with particular reference to lymph node involvement. Arch Pathol Lab Med 1982;106;261-4.

2 Azzopardi JG, Ross CMD, Frizzera G. Blue nevi of lymph node capsule. Histopathology 1977;1:437-61.

3 Leifer C, Miller AS, Putong PB, Min BH. Spindle cell carcinoma of the oral mucosa. A light and electron microscopic study of apparent sarcomatous metastasis to microscopic study of apparent sarcomatous me

4 Hsu S-M, Raine L, Fanger H. Use of avidin-biotin-peroxidase complex (ABC) in immunoperoxidase technique. A comparison between ABC and unlabeled antibody (PAP) procedures. J Histochem Cytochem 1981;29:577-80.

5 Weiss SW, Gnepp DR, Bratthauer GL. Palisaded myofibroblastoma. A benign mesenchymal tumor of lymph node. Am J Surg Pathol 1989;13:341-6.

6 Suster S, Rosai J. Intranodal hemorrhagic spindle-cell tumor with "amianthoid" fibers. Report of six cases of a distinctive mesenchymal neoplasm of the inguinal region that simulates Kaposi's sarcoma. Am J Surg Pathol 1989;13:347-57.

7 Amazon $\mathrm{K}$, Rywlin AM. Lymph node involvement in Kaposi's sarcoma. Am J Dermatopathol 1979;1:173-6.

8 Gabbiani G, Ryan GB, Maino G. Presence of modified fibroblasts in granulation tissue and their possible role in fibroblasts in granulation tissue and their possibl

9 Gabbiani G, Majno G. Dupuytren's contracture: fibroblast contraction? An ultrastructural study. Am J Pathol 1972;66:131-46

10 Oda D, Gown AM, Vande Berg JS, Stern R. The fibroblastlike nature of myofibroblasts. Exp Mol Pathol 1988, 49:316-29.

11 Schurch W, Semayer TA, Lagacé R, Gabbiani G. The intermediate filament cytoskeleton of myofibroblasts: an immunoflourescence and ultrastructural study. Virchows Arch (Pathol Anat) 1984;403:323-36.

12 Skalli O, Schurch W, Seemayer T, et al. Myofibroblasts from diverse pathologic settings are heterogeneous in their proteins. Lab Invest 1989;62:275-85.

13 Levi-Schaffer F, Kupietzky A. Mastcells enhance migration and proliferation of fibroblasts into an in vitro wound. Exp
Cell Res 1990;188:42-9.

14 Roche WR. Mast cells and tumors. The specific enhancement of tumor proliferation in vitro. Am J Pathol 1985;119. of tum. 64 . 